\title{
Effect of snoring on pregnancy-induced hypertension and feto-maternal outcomes
}

Renu Arora', Megha Gupta', Jyotsna Suri ${ }^{1,}$, J.C. Suri ${ }^{2}$ and Tulsi Adhikari ${ }^{3}$

1. Department of Obstetrics and Gynaecology, Vardhman Mahavir Medical College and Safdarjung Hospital, New Delhi 110029, India

2. Department of Pulmonary, Critical Care and Sleep Medicine, Vardhman Mahavir Medical College and Safdariung Hospital, New Delhi 110029, India

3. Indian Council of Medical Research, Ansari Nagar, New Delhi 110029, India

DOI No: 10.5958/0974-0155.2015.00022.4

Indian J Sleep Med 2015; 10.4, 159-164

\begin{abstract}
Objectives/Background: Snoring is a hallmark of Sleep Disordered Breathing (SDB) and is seen more often in pregnancy. This study was conducted to determine the frequency of snoring in pregnancy-induced hypertension and to observe its impact on feto-maternal outcomes.

Participants/Methods: Sixty-five women with preeclampsia and gestational hypertension comprised the study group, whereas 85 normotensive, age, and gestation matched women were the controls. All the subjects were questioned about habitual snoring and they were followed to study their feto-maternal outcomes.

Results and Conclusions: Snoring was seen more frequently in the cases (OR 16.9, 95\% Cl 6.8-41.7) as compared to controls even after controlling for BMI. The severity of hypertension was more in snorers $(p=0.021)$. The adverse pregnancy outcomes were more severe in the snorers in the cases as well as the controls. The fetal outcomes were more severely affected by snoring.

Conclusions: Snoring is more prevalent among women with pregnancy-induced hypertension and is associated with more severe hypertension and adverse outcomes.

Keywords: Preeclampsia, Gestational hypertension, Pregnancy induced hypertension, Snoring, Sleep-disordered breathing, Feto-maternal outcomes.
\end{abstract}

\section{Introduction}

S leep Disordered Breathing (SDB) is a spectrum of respiratory abnormalities due to the partial or complete collapse of the upper airway during sleep leading to intermittent hypoxia and fragmentation of sleep.

Address for correspondence

Dr Jyotsna Suri

D-II/153, West Kidwai Nagar, NewDelhi -

110023 , India.

E-mail: iyotsnasuri@gmail.com (J. Suri)
These disorders are commonly seen in pregnant women, particularly in the 3rd trimester. The increased prevalence of SDB during pregnancy has been attributed to weight gain, narrowing of the upper airway due to pharyngeal edema and increased upper airway resistance ${ }^{1-4}$.

Habitual snoring is considered as the hallmark of SDB. It has been seen that snoring is strongly associated with polysomnographic derived apnea-hypopnea index (AHI) and in women who report snoring as often or usual, it is associated with polysomnography (PSG) confirmed SDB with an OR of 3.8 and 16.3, respectively ${ }^{5,6}$. 
Snoring has been reported to occur more frequently in pregnancy and has been associated with poor pregnancy outcomes like preeclampsia and gestational hypertension ${ }^{7-15}$. Studies from Europe and North America have reported significantly higher rates of snoring in pregnant women as compared to age-matched, non-pregnant women ${ }^{10-13}$. In studies conducted on Indian population, snoring was found in $18-27.5 \%$ of pregnant women $^{14,15}$. It is also to note that snoring is often underreported in females due to cultural and social factors ${ }^{16}$.

$\mathrm{SDB}$ is associated with many cardiovascular manifestations including hypertension, coronary artery disease, and strokes ${ }^{17-19}$. It has been postulated that repeated episodes of hypoxia and arousal during sleep lead to sympathetic activation, oxidative stress, and endothelial dysfunction which may be responsible for the development of hypertension.

Preeclampsia and gestational hypertension are disorders, which manifest first time during pregnancy and affect about $7-10 \%$ of all pregnant women ${ }^{20,21}$. The pathogenesis of preeclampsia has eluded generations of researchers, but the most accepted mechanism which is described is triggered by the defective trophoblastic invasion of the placenta leading to a cascade of inflammatory changes and endothelial dysfunction ${ }^{22}$.

Preeclampsia is one of the most important causes of maternal and fetal morbidity and mortality ${ }^{23}$. The poor maternal outcomes include, eclampsia, antepartum hemorrhage, postpartum hemorrhage, and induced and operative deliveries, whereas the adverse fetal outcomes are intrauterine growth restriction (IUGR), preterm delivery, low birth weight, and need for nursery admission for the baby ${ }^{23-25}$.

Recent studies have reported that snoring is seen more commonly in women with preeclampsia ${ }^{26-29}$. Both SDB and preeclampsia have several features in common. The pathogenesis of hypertension in both the conditions is similar and there is overlapping of risk factors. Moreover, both are seen more often with advancing gestational age and are associated with adverse pregnancy outcomes.

There is only scanty evidence regarding the association of snoring with the maternal and fetal outcomes in preeclampsia, even though some studies have seen poor maternal and fetal outcomes in pre-eclamptic women suffering from $\mathrm{SDB}^{30}$. Diagnosis of SDB requires a full night polysomnography which is often difficult to perform in pre-eclamptic women due to logistic and emergent clinical reasons. Hence, we decided to use snoring as a surrogate marker for SDB. It was hypothesized that snoring would be more prevalent in women with preeclampsia and would be associated with worse maternal and fetal outcomes.

\section{Methods}

\subsection{Participants}

This was a prospective, case-control study which was conducted at Vardhman Mahavir Medical College and Safdarjung Hospital, New Delhi. Patients with preeclampsia or gestational hypertension in the age group, 18-35 years, who attended the antenatal OPD or admitted as in-patients were serially screened and those who met the inclusion criteria were offered to be part of the study. Ethical clearance from the institutional ethical committee was taken before commencing the study.

A total of 78 patients fulfilled the criteria and of these 65 gave their consent to be part of the study. The demographic and clinical profile of the women who did not give their consent was similar to that of the others.

Women with chronic or acute respiratory diseases, overt or gestational diabetes, renal disease, liver disease, heart disease, essential hypertension or any other medical or obstetrical condition known to have poor pregnancy outcomes were excluded from the study.

Gestational hypertension was defined as a blood pressure of $\geq 140 / 90 \mathrm{mmHg}$ on two or more occasions 6 hours apart, detected first after 20 weeks of pregnancy; whereas preeclampsia was diagnosed when hypertension was accompanied by albuminuria of $1+$ or more on dipstick examination.

The control group consisted of age and gestation period matched normotensive pregnant women with no medical disease, attending the antenatal OPD. Out of 104 women who fulfilled the criteria, 85 agreed to be part of the study.

\subsection{Subject evaluation}

All the women underwent a detailed general physical, systemic, and obstetric examination.The subjects were asked about the presence of habitual snoring, defined as snoring more than 3-4 times a week ${ }^{31-32}$. All the cases were administered standard care for preeclampsia and gestational hypertension. 
The subjects were kept under follow up and the maternal and fetal outcomes during pregnancy, labor, and the postnatal period were recorded. These maternal and fetal outcomes were- preterm labor, antepartum hemorrhage, postpartum hemorrhage, eclampsia, intrauterine growth restriction, birth weight of neonate, APGAR score, mode and route of delivery, and the requirement for nursery admission.

\subsection{Statistical Analysis}

Comparison of demographic parameters between cases and controls was done using the student's t-test and Chisquare test. The comparison was also done after adjustment for the BMI comparison of maternal and fetal complications including BP between snorers and non-snorers in cases and controls separately were done using Chi-square test and student's t-test.

\section{Results}

Table 1: Comparison of demographic parameters and snoring between cases and controls.

\begin{tabular}{|l|l|l|l|l|}
\hline $\begin{array}{l}\text { Demographic } \\
\text { parameters }\end{array}$ & $\begin{array}{l}\text { Cases } N=65 \\
(\text { mean } \pm \text { SD })\end{array}$ & $\begin{array}{l}\text { Controls } \\
N=85 \\
(\text { mean } \pm \\
S D)\end{array}$ & $\begin{array}{l}p \text {-value } \\
\text { OR) CI } \\
\text { of OR }\end{array}$ & $\begin{array}{l}p \text {-value } \\
\text { after } \\
\text { adjustment } \\
\text { for BMI } \\
(\text { OR })(C I \\
\text { of OR })\end{array}$ \\
\hline Age $($ years $)$ & $26.0 \pm 3.9$ & $25.3 \pm 3.4$ & 0.309 & \\
\hline BMI $\left(\mathrm{kg} / \mathrm{m}^{2}\right)$ & $26.0 \pm 2.3$ & $24.7 \pm 2.0$ & 0.001 & \\
\hline POG $($ weeks $)$ & $34.0 \pm 2.4$ & $34.3 \pm 2.7$ & 0.450 & \\
\hline SBP $(\mathrm{mm} \mathrm{Hg})$ & $144.7 \pm 6.6$ & $107.5 \pm 6.5$ & $<0.001$ & 0.992 \\
\hline DBP $(\mathrm{mm} \mathrm{Hg})$ & $94.1 \pm 4.4$ & $68.9 \pm 6.2$ & $<0.001$ & 0.991 \\
\hline MBP $(\mathrm{mm} \mathrm{Hg})$ & $110.9 \pm 4.6$ & $81.8 \pm 5.6$ & $<0.001$ & 0.992 \\
\hline Snoring & $67.1 \%$ & $10.8 \%$ & $\begin{array}{l}<0.001 \\
(\mathrm{OR}=16.9) \\
(6.8,41.7)\end{array}$ & $\begin{array}{l}<0.001 \\
(15.6) \\
(6.0,40.7)\end{array}$ \\
\hline
\end{tabular}

BMI : Body Mass Index; POG : Period of Gestation; SBP : Systolic Blood Pressure; DBP : DiastolicBlood Pressure; MBP: Mean Blood Pressure

It was observed that snoring occurred more frequently in the patients with preeclampsia as compared to the normotensive pregnant women, even after adjustment for BMI (OR 16.9, 95\% CI 6.8-41.7). The age and period of gestation in both groups was comparable. The blood pressure values were predictably higher in the cases but interestingly this difference became insignificant on adjusting for BMI, signifying the role of BMI in the development of hypertension (Table 1).
Table 3: Maternal and fetal outcomesin cases and controls.

\begin{tabular}{|c|c|c|c|c|c|}
\hline & \multicolumn{2}{|c|}{$\begin{array}{l}\text { Cases } n \\
=65\end{array}$} & \multicolumn{2}{|c|}{$\begin{array}{c}\text { Controls } n \\
=85\end{array}$} \\
\hline & & $\%$ & $p$-value & $\%$ & $p$-value \\
\hline \multirow[t]{2}{*}{ LSCS } & Snorers & 47.4 & \multirow[t]{2}{*}{0.7} & 28.6 & \multirow{2}{*}{0.462} \\
\hline & Non-snorers & 42.9 & & 17.2 & \\
\hline \multirow{2}{*}{$\begin{array}{l}\text { Spontaneous } \\
\text { delivery }\end{array}$} & Snorers & 19.9 & \multirow[t]{2}{*}{0.025} & 71.4 & \multirow{2}{*}{0.462} \\
\hline & Non-snorers & 42.9 & & 82.8 & \\
\hline \multirow{2}{*}{$\begin{array}{l}\text { Induced } \\
\text { delivery }\end{array}$} & Snorers & 33.3 & \multirow[t]{2}{*}{0.063} & & \\
\hline & Non-snorers & 14.3 & & & \\
\hline \multirow[t]{2}{*}{ IUGR } & Snorers & 49.1 & \multirow[t]{2}{*}{0.034} & 71.4 & \multirow{2}{*}{0.001} \\
\hline & Non-norers & 25.0 & & 10.5 & \\
\hline \multirow[t]{2}{*}{ APGAR $<=7$} & Snorers & 54.4 & \multirow[t]{2}{*}{0.053} & 57.1 & \multirow{2}{*}{0.034} \\
\hline & Non-snorers & 32.1 & & 17.2 & \\
\hline \multirow[t]{2}{*}{$\begin{array}{l}\text { Birth weight } \\
<2.5 \mathrm{~kg}\end{array}$} & Snorers & $\begin{array}{l}2.38+ \\
0.43\end{array}$ & \multirow[t]{2}{*}{0.684} & $\begin{array}{l}2.44+ \\
0.98\end{array}$ & \multirow{2}{*}{$<0.001$} \\
\hline & Non-snorers & $\begin{array}{l}2.43+ \\
0.59\end{array}$ & & $\begin{array}{l}2.76+ \\
0.30\end{array}$ & \\
\hline
\end{tabular}

LSCS: Lower segment caesarean section; IUGR : Intrauterinegrowthrestriction

We further decided to study the association of pregnancy outcomes with snoring. It was seen that the snorers consistently fared poorly for induced delivery, intrauterine growth restriction and anAPGAR score $<7$ in the cases. A similar trend was observed for LSCS and birth weight $<2.5 \mathrm{~kg}$ though insignificant. Notably, the snorers in the control group also suffered from adverse pregnancy outcomes (Table 3).

\section{Discussion}

This was a prospective, case-control study in which it was observed that snoring occurred more frequently in women with new-onset hypertension of pregnancy. This difference remained significant even after controlling for BMI, further strengthening the association of snoring and preeclampsia, as obesity is a common risk factor for both conditions. We also observed that the severity of hypertension was more in the pre-eclamptic women with snoring. Further, on studying the association of pregnancy outcomes with snoring, it was seen that women who snored had significantly higher adverse outcomes as compared to none-snorers in cases as well as the controls.

Indian Journal of Sleep Medicine (IJSM), Vol. 10, No. 4, 2015 
Snoring is a manifestation of narrowing of the upper airway during sleep, as a result of sleep-specific changes in the function of upper airway or due to a narrower upper airway even in the wakeful state ${ }^{33}$. It has been observed by many that pregnant women have a higher prevalence of snoring as compared to their non-pregnant counterparts $^{7-9}$. This could be because of the anatomical and physiological changes during pregnancy leading to narrowing of the airway ${ }^{1-4}$. These changes may be further accentuated in preeclampsia due to fluid shifts from the lower limbs to the neck area ${ }^{34}$. Izci et al., ${ }^{35}$ noted that the caliber of the upper airway was significantly smaller in the pre-eclamptic pregnant women as compared to normotensive pregnant women and non-pregnant women. The reason for this may be tissue edema, though differential fat deposition also has to be considered. Imaging studies would be useful to determine the nature of the soft tissue deposits in these patients.

We too observed an increased frequency of snoring in preeclampsia, (OR 16.6, $p<0.001$ ), even after controlling for obesity, which is one of the major risk factor for snoring and $\mathrm{SDB}^{36-39}$. It is possible that the snoring may lead to repeated arousals with resultant surges in the blood pressure leading to an exacerbation of blood pressure in the pre-eclamptic women ${ }^{40,41}$. This may explain our observation of an increased severity of hypertension in the snorers. Even though the association of snoring with preeclampsia has been well established in our study and by previous authors, it is difficult to determine the directionality of the relationship without interventional studies ${ }^{10-14}$. Preliminary reports though suggest an improvement of blood pressure in cases of preeclampsia on nasal C-PAP therapy ${ }^{40}$.

Preeclampsia is known to be associated with poor pregnancy outcomes. To determine whether snoring worsens these outcomes, we studied the relationship between snoring and some maternal and fetal outcomes. Not surprisingly, a significant association was observed between snoring and adverse pregnancy outcomes in the cases. Similar trends were also seen in the control group. However, the exact mechanism responsible for this needs to be further studied with detailed PSG to determine the individual contribution of airflow limitation, gas exchange abnormalities, and sleep fragmentation in the causation of poor pregnancy outcomes.

It was noteworthy that the impact of snoring was more significant for fetal outcomes as compared to maternal outcomes. This may be explained by the observations of a recent study which found a significant association of maternal snoring with enhanced fetal erythropoiesis ${ }^{42}$. Erythropoiesis occurs during periods of hypoxia and is associated with intrauterine growth restriction ${ }^{43}$. Thus it appears that adverse fetal outcomes may be more sensitive to snoring with repeated episodes of maternal apnea during snoring may lead to fetal hypoxia.

The strength of our study lies in the prospective design and the fact that we followed the subjects till they delivered, hence defining the outcomes. The major limitation was the use of symptom-based screening rather than a PSG to study the pregnancy outcomes. However, this in itself has got very practical implications. It is logistically difficult to make all pre-eclamptic women undergo a full night, in-lab PSG; using snoring as a surrogate has given us an insight into the contribution of SDB towards poorer outcomes in preeclampsia. Hence, we can recommend that all pregnant women with pregnancy-induced hypertension should be screened for SDB by taking the history of snoring, followed by a full night PSG which can reveal the exact magnitude of the problem. Interventional studies are also warranted to see the impact of C-PAP treatment on maternal and fetal outcomes in preeclampsia.

To summarize it was observed that snoring was seen more frequently in women with preeclampsia. Further, it was seen that the women who snored had more severe hypertension and poorer pregnancy outcomes as compared to women with preeclampsia who did not snore. Hence, it is recommended that all pre-eclamptic women who snore should be evaluated for the presence of SDB by PSG or an equivalent test.

\section{References}

1. Izci B, Vennelle $M$, Liston WA, et al. Sleep-disordered breathing and upper airway size inpregnancy and postpartum. EurRespir J 2006; 27:321.

2. Pilkington $S$, Carli F, Dakin MJ, et al. Increase in Mallampati score during pregnancy. Br J Anaesth 1995; 74:638.

3. Facco FL, Kramer J, Ho KH, et al. Sleep disturbances in pregnancy. ObstetGynecol 2010; 115:77.

4. David $\mathbf{P}$ White. Pathogenesis of obstructive and centralsleepapnea Am J Respir Crit Care Med $2005 ; 172(11): 1363-70$.

5. Nieto FJ, Young TB, Lind BK, et al. Association of sleepdisordered breathing, sleep apnea, and hypertension in a large community-based study. Sleep Heart Health Study. JAMA. 2000;283(14):1829-36. 
6. Bliwise DL, Nekich JC, Dement WC. Relative validity of self-reported snoring as a symptom of sleep apnea in a sleep clinic population. Chest 1991;99(3):600-8.

7. Hedman C, Pohjasvaara T, Tolonen U, Suhonen-Malm AS, Myllyla VV. Effects of pregnancy on mothers' sleep. Sleep Med 2002; 3(1):37-42. [PubMed: 14592252]

8. Pien GW, Fife D, Pack Al, Nkwuo JE, Schwab RJ. Changes in symptoms of sleep-disordered breathing during pregnancy. Sleep 2005; 28(10):1299-305. [PubMed: 16295215]

9. Loube DI, Poceta JS, Morales MC, Peacock MD, Mitler MM. Self-reported snoring in pregnancy association with fetal outcome. Chest 1996;109:885-9.

10. Franklin KA, Holmgren PA, Jonsson F, Poromaa N, Stenlund $H$, Svanborg E. Snoring, pregnancyinduced hypertension, and growth retardation of the fetus. Chest 2000; $117(1): 137-41$.

11. Louise M O'Brien, Alexandra S Bullough, Jocelynn T Owusu, Kimberley A Tremblay,Cynthia A Brincat,Mark C Chames, John D Kalbfleisch, Ronald D Chervin.Pregnancyonsethabitualsnoring, gestationalhypertension, andpreeclampsia: prospectivecohortstudy. Am J Obstet Gynecol 2012 ; 207(6): 487.

12. Calaora-Tournadre D, Ragot S, Meurice JC, et al. Obstructive sleep apnea syndrome during pregnancy: prevalence of main symptoms and relationship with pregnancy-induced-hypertension and intra-uterine growth retardation. Rev Med Interne 2006; 27: 291-5.

13. Schutte S, Del Conte A, Gross A, et al. Self-reported snoring and sleep in high-risk pregnancies. Sleep Res 1995; 24: 342 .

14. Aggarwal M, Suri JC,Suri S, Sen MK. Maternal and fetal outcomesof sleep-disordered breathing in pregnancy. Indian J Sleep Med 2008;3(1):25-9.

15. Suri JC, Sen MK, Suri J, Vaidya S, Adhikari T. Epidemiology of sleep disorders in pregnant patients: a questionnairebased survey. Indian J Sleep Med2009; 4(3):106-1.

16. Young T, Evans L, Finn L, Palta M. Estimation of the clinically diagnosed proportion of sleep apneasyndrome in middleaged men and women. Sleep 1997; 20(9):705-6.

17. Peppard PE, Young T, Palta M, Skatrud J. Prospective study of the association between sleep-disordered breathing and hypertension. N Engl J Med 2000;342(19):1378-84.

18. Newman AB, Nieto FJ, Guidry U, et al. Relation of sleepdisordered breathing to cardiovascular disease risk factors: the SleepHeartHealthstudy. Am J Epidemiol 2001; 154(1):50-9

19. Young T, Peppard P. Sleep-disordered breathing and cardiovascular disease: epidemiologic evidence for a relationship. Sleep 2000;23(Suppl 4):S122-S126.

20. Granger JP, Alexander BT, Llinas MT, Bennett WA, Khalil RA. Pathophysiology of preeclampsia: linking placental ischemia/hypoxia with microvascular dysfunction. Microcirculation 2002;9:147-60.

21. Hypertension in pregnancy Report of the American College of Obstetricians and Gynaecologists' Task Force on
Hypertension in Pregnancy. ObstetGynecol 2013; $122: 1122$.

22. Powe CE, Levine RJ, Karumanchi SA. Preeclampsia, a disease of the maternal endothelium: the role of antiangiogenic factors and implications for later cardiovascular disease. Circulation $2011 ; 123(24): 2856-69$.

23. Khan KS, Woidyla D, Say L, Gulmezoglu AM, Van Look PF. WHO analysis of causes of maternal death: a systematic review. Lancet 2006;367(9516):1066-74.

24. L. Duley. Pre-eclampsia and the hypertensive disorders of pregnancy. Br Med Bull 2003;67:161-76.

25. Sibai BM, Caritis S, HauthJ. What we have learned about preeclampsia, Seminars in Perinatology 2003;27(3):239-46.

26. Izci B, Martin SE, Dundas KC, Liston WA, Calder AA, Douglas NJ. Sleep complaints: snoring and daytime sleepiness in pregnant and pre-eclamptic women. Sleep Med 2005;6(2): 163-9.

27. Facco FL, Kramer J, Ho KH, Zee PC, Grobman WA. Sleep disturbances in pregnancy. Obstet Gynecol $2010 ; 115(1): 77-83$.

28. Sahota PK, Jain SS, Dhand R. Sleep disorders in pregnancy. CurrOpinPulm Med 2003;9(6):477-83.

29. Santiago JR, Nolledo MS, Kinzler W, Santiago TV. Sleep and sleep disorders in pregnancy. Ann Intern Med $2001 ; 134(5): 396-408$.

30. Bourjeily G, Raker CA, Chalhoub M, Miller MA. Pregnancy and fetal outcomes of symptoms of sleep-disordered breathing. EurRespir J 2010;36(4):849-55.

31. Kump K, Whalen C, Tishler PV, Browner I, Ferrette V, Strohl $\mathrm{KP}$, et al. Assessment of the validity and utility of a sleepsymptom questionnaire. Am J Respir Crit Care Med $1994 ; 150(3): 735-41$.

32. Young $T$, Shahar $E$, Nieto FJ, Redline $S$, Newman $A B$, Gottlieb DJ, et al. Predictors of sleep-disordered breathing in community-dwelling adults: the sleephearthealth study. Arch Intern Med 2002;162(8):893-900.

33. Bradley TD, Brown IG, Grossman RF, Zamel N, Martinez D, Phillipson EA, Hoffstein V. Pharyngeal size in snorers, nonsnorers, and patients with obstructive sleep apnea. $\mathrm{N}$ Engl J Med 1986;315:1327-31.

34. Louis JM, Mogos MF, Salemi JL, et al. Obstructive sleep apnea and severe maternal-infant morbidity/mortality in the United States, 1998-2009. Sleep 2014; 37:843.

35. Bilgaylzci, Renata L Riha, Sascha E Martin, Marjorie Vennelle, Wang A Liston, Kirsty C Dundas, Andrew A Calder, Neil J Douglas. The upperairway in pregnancy and pre-eclampsia. Am J Respir Crit Care Med 2003;167(2):137-40.

36. Vgontzas AN, Papanicolaou DA, Bixler EO, et al. Sleep apnea and daytime sleepiness and fatigue: relation to visceral obesity, insulin resistance, and hypercytokinemia. J ClinEndocrinolMetab 2000;85:1151-8.

37. Jordan AS, White DP, Fogel RB. Recent advances in understanding the pathogenesis of obstructive sleep apnea. CurrOpinPulm Med 2003;9:459-64.

Indian Journal of Sleep Medicine (IJSM), Vol. 10, No. 4, 2015 
38. Young T, Peppard PE, Taheri S. Excess weight and sleepdisordered breathing. J ApplPhysiol 2005;99:1592-9.

39. Newman AB, Foster G, Givelber R, Nieto FJ, Redline S, Young T. Progression and regression of sleep-disordered breathing with changes in weight: the sleephearthealthstudy. Arch Intern Med 2005; 165: 2408-13.

40. Edwards N, Blyton DM, Kirjavainen T, Kesby GJ, Sullivan CE. Nasal continuous positive airway pressure reduces sleep-induced blood pressure increments in preeclampsia. Am J RespirCrit Care Med 2000;162(1):252-7.
41. Edwards N, Blyton DM, Kirjavainen T, Sullivan CE. Hemodynamic responses to obstructive respiratory events during sleep are augmented in women with preeclampsia. Am J Hypertens 2001;14:1090-5.

42. Tauman R, Many A, Deutsch V, Arvas S, Ascher-Landsberg $J$, Greenfeld $M$, et al. Maternal snoring during pregnancy is associated with enhanced fetal erythropoiesis-a preliminary study. Sleep Med2011;12(5):518-22.

43. Hermansen MC. Nucleated red blood cells in the fetus and newborn. Arch Dis Child Fetal Neonata Ed2001;84(3):F211-5. 